\title{
Anomalies of oxygen measurements performed with Aanderaa optodes
}

\author{
N. Lo Bue ${ }^{1}$, N., A. Vangriesheim ${ }^{2}$, A. Khripounoff ${ }^{2, *}$, T. Soltwedel $^{3}$ \\ ${ }^{1}$ Istituto Nazionale di Geofisica e Vulcanologia, Rome, Italy \\ 2 Ifremer centre de Brest, Département DEEP/LEP Plouzané, France \\ ${ }^{3}$ Alfred Wegener Institute for Polar and Marine Research, Bremerhaven, Germany \\ *: Corresponding author : Alexis Khripounoff, email address : Alexis.Khripounoff@ifremer.fr
}

\begin{abstract}
:
Four sets of measurements performed between 2005 and 2010 in the deep central Atlantic, the deep north-western Mediterranean Sea, and in the Arctic Ocean revealed strange anomalies in the performance of the Aanderaa optode 3830 sensors mounted on RCM11 current meters in low current regimes (current speeds $>10 \mathrm{~cm} \mathrm{~s}^{-1}$ ). All oxygen datasets collected during these deployments showed significant drops of oxygen (50-100 $\mu \mathrm{mol})$ affecting the data stability of the optode sensors in low hydrodynamic conditions.
\end{abstract}

High correlations between all acquired parameters (temperature, turbidity, speed and direction of currents) verified that no unusual event occurred in the mooring areas during the periods of acquisition, although natural events responsible for such abrupt, short and intense oxygen variations cannot be easily identified. Despite the well-known performance of the Aanderaa optodes, these experiments demonstrate that the data acquired by those installed on RCM11s cannot be always reliable, especially in low energy systems (typical for the deep ocean), and that current speeds should always be considered in order to verify the reliability of the data recorded.

Keywords : Oxygen, optode, deep-sea, currents, long-term measurement

\section{Introduction}

Although the principle of fluorescence quenching is known for a long time, it has been applied to seawater technology only within in the last years.

There already exists a large body of literature featuring the use and performance of optical oxygen measurements in seawater achieved through fluorescence quenching based sensors, like the 
Aanderaa optode (ATC, 2004; Hydes et al., 2009; Körtzinger et al., 2005; Körtzinger et al., 2004; Martini et al., 2007; Schmidt et al., 2008; Soltwedel et al., 2005; Tengberg et al., 2006; Tengberg et al., 2003; Uchida et al., 2008; Vangriesheim, 2007)

Unfortunately in most of this literature, complementing data on hydrodynamic conditions are missing.

On the bases of its widely documented efficiency, optodes were used in different scientific programs carried out by the Ifremer/DEEP laboratory and the Deep-Sea Research Group at the Alfred Wegener Institute for Polar and Marine Research from 2005 to 2010 in order to exploit their good performance on long-term measurements monitoring oxygen concentration in deep seawater (EXOMAR 2005: biological exploration and characterisation of hydrothermal environment of the Mid-Atlantic Ridge; ENVAR 2005-2007: study of the Var deep canyon ecosystem; DEEP 2009: study of the sediment input from the Rhone river to the deep Gulf of Lions; HAUSGARTEN: timeseries studies at an arctic deep-sea site, Fram Strait / Arctic Ocean).

Here are reported long-term oxygen data recorded by optodes mounted on RCM11 acoustic current meters moored in various environments thereby showing the same kind of doubtful results at comparable hydrodynamic conditions.

\section{Material and methods}

\subsection{Measurement sites and moorings:}

During the EXOMAR research program conducted on the Mid-Atlantic Ridge in 2005, four moorings were deployed at increasing distance from the Tour Eiffel chimney of the Lucky Strike hydrothermal vent field $\left(37^{\circ} 17^{\prime} \mathrm{N}, 32^{\circ} 16^{\prime} \mathrm{W}\right)$, with the main aim to better explore and understand the environment of hydrothermal micro-organisms (Fig. 1a). Two moorings were equipped with 
current meters, one of which (RCM11 s/n 177) carried an Aanderaa optode 3830. This latter mooring, handled by the Remotely Operated Vehicle (ROV) "Victor 6000", was deployed $5 \mathrm{~m}$ southward (1700 m water depth) from the Tour Eiffel chimney at $15 \mathrm{~m}$ above the bottom and acquired a series of oxygen data over 25 days with a sampling rate of 1 sample each 10 minutes (Vangriesheim, 2007).

The ENVAR program, as part of the European HERMES project, focused on the study of turbidity events in the Var submarine canyon (Fig. 1b) and its effects on the deep benthic ecosystems. During two years (between 2005 and 2007) several long-term moorings were repeatedly deployed at different depths along the Var canyon axis. Among other instruments, the moorings were equipped with mechanical current meters (Aanderaa RCM8) and turbidity meters. At two sites (VA, 43 $22^{\prime}$

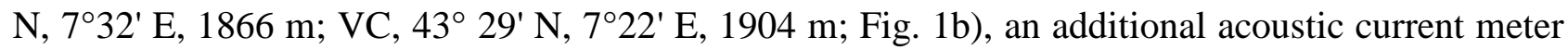
(Aanderaa RCM11 s/n 542) was intermittently attached to the moorings (at $\sim 460 \mathrm{~m}$ and $\sim 260 \mathrm{~m}$ above bottom, respectively), in order to compare the efficiency of mechanical and acoustic current measurements.

As for the previous experiment, the RCM11 was equipped with an optode sensor 3830, thus oxygen data were collected by the same sensor in two different time periods (May-August 2006 at VC site, and August-November 2006 at VA site) with a sampling rate of 1 sample each 30 minutes (Vangriesheim, 2007).

In 2008, the French Agence Nationale de la Recherche (ANR) funded the EXTREMA research program to study the sedimentary mass transported by the Rhone river into the Gulf of Lions, NW Mediterranean. In this framework, the Ifremer/DEEP activities focused on the particle input at two different stations located at the base of the margin (Station $\mathrm{A}, 42^{\circ} 10^{\prime} \mathrm{N}, 4^{\circ} 33^{\prime} \mathrm{E}, 2256 \mathrm{~m}$ ) and at the confluence of two submarine canyons (Creus and Sète, Station B, 42 ${ }^{\circ} 15^{\prime} \mathrm{N}, 4^{\circ} 20^{\prime} \mathrm{E}, 2197 \mathrm{~m}$ ), respectively (Fig. 1c). In total, three moorings were deployed at these sites (one at Station A, and two at the Station B) in order to study the local current regime and to determine the flux of particulate matter to the seafloor. Each of these moorings carried an acoustic current meter 
(Aanderaa RCM11 s/n 177 s/n 542, and s/n 625) equipped with optode 3830 at $30 \mathrm{~m}$ above the bottom.

Within the frame of the time-series work at the deep-sea long-term observatory HAUSGARTEN west of Svalbard (Soltwedel et al., 2005), two Aanderaa RCM11 (s/n 691 and s/n 692) with optode sensors 3830 were deployed at the shallowest and the central HAUSGARTEN site, respectively (HG-I, 79 08,02' N, 6 05,59' E, 1282 m; HG-IV, 79 04,83' N, 0405,41' E, 2467 m) (Fig. 1d). Both instruments were fixed at about $2 \mathrm{~m}$ above ground on top of free-falling devices (bottomlander) deployed for one year between the summers of 2009 and 2010.

\subsection{Calibration:}

The calibration of optode sensors were performed according to the Aanderaa protocol consisting in two points of measurements: Zero oxygen saturation, adding small quantity of Thiosulfate at the calibration bath, and $100 \%$ oxygen saturation, through the injection of air in the calibration. In both cases oxygen concentrations were calculated as a function of temperature and salinity through the Aanderaa software OXYWIEW 6.

Except for the RCM11 s/n 625 bought on the occasion of DEEP research program and for optodes mounted on RCM $11 \mathrm{~s} / \mathrm{n} 691$ and 692) specifically bought and used for the first time in HASGARTEN experiments, the other sensors were repeatedly used through all different deployments, however, a complete calibration and foil check was performed only before the DEEP experiment (RCM11 s/n 177, and s/n 542). 


\section{Results}

\subsection{Data collected during the EXOMAR experiment:}

During 25 days of deployment several parameters (temperature, current speed, current direction, and oxygen) have been acquired by the Aanderaa RCM11 close to the hydrothermal Tour Eiffel chimney (Mid-Atlantic Ridge). Among these parameters, oxygen and temperature data showed abrupt variations starting from a quite stable mean value (about $307 \mu \mathrm{M}$ and about $4.3^{\circ} \mathrm{C}$ ). Several drops occurred in the oxygen readings (Fig. 2a), showing variations between 20 and $100 \mu \mathrm{M}$ occurring in a few tens of minutes. At the same time, temperature data readings exhibited many peaks with increasing values of up to $1^{\circ} \mathrm{C}$ from the mean value.

A comparison between all data recorded revealed that temperature and oxygen variations are not concurrent. In fact, peaks in temperature do not occur simultaneously with oxygen drops but seem to be in completely accordance with variations in current speed. Looking closer at the data (Fig. $2 \mathrm{~b}$ ), it is also possible to note that all oxygen drops seems to arise in correspondence with low current speeds and a particular current orientation $\left(>250^{\circ}\right)$.

\subsection{Data collected during the ENVAR experiment:}

Data recorded at two different sites of the Var submarine canyon (VA and VC; Fig. 1b) showed generally stable oxygen values of about $230 \mu \mathrm{M}$, episodically interrupted by sudden drops reaching minimum values of $\sim 147 \mu \mathrm{M}$ at $\mathrm{VC}$ and $\sim 170 \mu \mathrm{M}$ at VA (Figs 3a and b). According to the high homogeneity of Mediterranean bottom seawater, no significant temperature variations were found during the ENVAR experiment. Nevertheless, comparisons between oxygen and current data showed a good agreement between drops in oxygen concentrations and periods of comparably weak 
currents. At higher current velocities oxygen values remained stable and showed no anomalies in the signal. This behaviour is clearly visible in the oxygen series collected at VC site (Fig. 3a), but only hard to see in the VA series because of a generally more noisy signal. At first sight, the oxygen drops might also be related to a particular current direction, as already observed in EXOMAR data.

\subsection{Data collected during DEEP experiment:}

Three different optode series collected in the Gulf of Lions showed similar strong anomalies during the first months of the deployment (Figs $4 \mathrm{a}$ and $\mathrm{b}$ ). This noisy period affected by several drops corresponded well with minimum current values recorded during the measurements (speed current $<5 \mathrm{~cm} \mathrm{~s}^{-1}$ ) and suddenly disappeared when current speeds increased.

For all oxygen sensors the mean oxygen concentration measured was of $\sim 200 \mu \mathrm{M}$. This value remained stable when current velocities exceeded $10 \mathrm{~cm} \mathrm{~s}^{-1}$ showing abrupt decreases in oxygen (in some case $>100 \mu \mathrm{M}$ ) for lower current speeds. Furthermore, drops in oxygen measured during the first months by all optodes mounted on RCM11 s/n 177, s/n 542 and s/n 625, seem in good agreement with continuous and rapid fluctuations of current direction.

\subsection{Data collected at HAUSGARTEN observatory:}

Optodes at the HAUSGARTEN sites were deployed for almost 12 months recording oxygen values at 1-h intervals, and revealed 8613 valid records for the shallower station (HG-I) and 8284 records at the deeper site (HG-IV). The instrument deployed at $1282 \mathrm{~m}$ water depth (HG-I) showed generally much more noise in the data, compared to the oxygen data retrieved at $2467 \mathrm{~m}$ depth (HG-IV) (Fig.5). As for the DEEP experiment, optode readings showed strongest anomalies immediately following the deployment of the sensors, in this case covering a time period of 1-2 
months. The mean oxygen values at HAUSGARTEN were about $7 \mu \mathrm{M}$ higher at HG-I $(279.9 \pm$ 14.9 $\mu \mathrm{M})$, compared to those obtained at HG-IV $(273.1 \pm 6.0 \mu \mathrm{M})$. Both readings showed several significant drops in oxygen (minimum values reached 130.6 $\mu \mathrm{M}$ at HG-I, and 148.9 $\mu \mathrm{M}$ at HG-VI) and an overall slight increase in oxygen concentrations between 2009 and 2010. Again, the comparison of optode data with current velocities registered by the RCM11 showed a close correlation between drops in oxygen concentrations and reduced current speeds below $10-12 \mathrm{~cm} \mathrm{~s}^{-1}$. No clear correlations could be found for oxygen values compared to water temperatures and current directions.

\section{Discussion and conclusion}

Aanderaa optodes 3830 mounted on RCM11 acoustic current meters deployed at various deep-sea sites in the Atlantic Ocean, the north-western Mediterranean Sea, and the Arctic Ocean showed several anomalies in their readings. All oxygen data exhibited episodic drops in oxygen concentrations lasting for varying time periods from minutes to days.

These drops were initially noticed during the EXOMAR experiment, where the good correlation between current speeds and temperature variations reflected the influence of the hydrothermal fluid activity: peaks in temperature occurred when current speeds suddenly increased, corresponding to the escaping of warmer water from the vent area. Surprisingly, during these events, oxygen showed unexpected stable values $(\sim 307 \mu \mathrm{M})$, while drops in oxygen were observed only during low temperature values $\left(\sim 4.3-4.5^{\circ} \mathrm{C}\right)$ confirming a complete independence from possible hydrothermal vent influence (Fig. 2). Other oxygen measurements were performed much closer to the hydrothermal vent using an optode connected to an independent data logger (NKE) with internal temperature sensor but without current speed. They showed the typical inverse correlation between temperature and oxygen under the direct influence of hydrothermal vents (P.M. Sarradin and C. Le 
Gall, Ifremer DEEP/LEP, personal communication), confirming that the drops observed during EXOMAR experiment can not be due to natural variations.

In order to exclude possible random peaks, a spectral analysis was performed on all data acquired at the hydrothermal vent site. The same periodicities related to the tidal effect $(\sim 20-26 \mathrm{~h}, \sim 12 \mathrm{~h}$ and $\sim$ 6h) appeared in all time-series recorded, showing that the observed variations were not associated to any instrumental noise (Vangriesheim, 2007).

The same behaviour was observed in ENVAR, DEEP and HAUSGARTEN series, where drops suddenly reached $\Delta \mathrm{O}_{2}$ values of $>80-100 \mu \mathrm{M}$ (Figs 3, 4 and 5). Also, the stability of temperature recorded in these time-series, excluded any possible correlation or influence of temperature variations on the occurrence of drops in oxygen.

The data collected in the Gulf of Lions (DEEP experiment) gave one of the best comprehensive examples of this correlation, showing once again the presence of oxygen drops occurring mainly in periods of weak and stable current below $5-10 \mathrm{~cm} \mathrm{~s}^{-1}$, while stable oxygen values occurred in time periods with increased current velocities (Fig. 6).

At first sight, the recorded drops in oxygen concentrations might as well be associated to abrupt changes in current direction. In fact, looking at the oxygen readings from the VC site (ENVAR experiment), it seems that the biggest drops recorded are in correspondence with period of minimum speed but also at changes in current orientation (Fig. 3a). A similar correlation was found for HAUSGARTEN and EXOMAR data. In this latter case, drops in oxygen mainly occurred when currents were oriented between $250^{\circ}$ and $350^{\circ}$ (Figs $2 \mathrm{a}$ and b). Figure 7 displays the relationship between current speeds and oxygen values versus current directions, showing that oxygen drops occurred in correspondence with low currents and specific current orientations (blue shaded area).

Looking at the data series in more detail (Figs 2-5), it becomes obvious that when current speeds decreased, current directions became more unstable and therefore mostly affected by sudden changes in direction. Consequently, the change in current orientation is not directly responsible for the drops in oxygen concentrations, but is simply an indirect effect induced by decreasing currents. 
The good agreement of data collected by acoustic (RCM11) and mechanical (RCM8) current meters allowed to validate the proper functioning of the sensors confirming the reliability of current velocity acquired (Vangriesheim, 2007). Moreover, to verify if the low speed values were due to an excess of particles reducing the acoustic signal, a comparison was made between speed and turbidity data during the ENVAR experiment. Turbidity was measured by two indirect means: the back-scatter signal recorded by the RCM11 and the turbidity data obtained by a turbidimeter (LSS connected to a NKE data logger) installed close to the RCM11. In both cases, low current speeds were not correlated to increased turbidity, and there was no relationship between drops in oxygen recorded by the optodes and data from the turbidity meter (Fig. 3b).

As mentioned at the beginning of this work, the existing literature on the use of the optode technology in marine studies showed that optode data were often obtained with satisfying results. Unfortunately it is not possible to use data presented by other authors for direct comparisons, because they often refer to shallow water environments focussed on high-energy systems or because simultaneous current measurements were missing. Only a recent experiment performed by Ifremer during the European program CoralFish offers a good opportunity of comparison (A. Khripounoff, unpublished data). In October 2009, a mooring carrying an Aanderaa RCM 11 (s/n 625) including the same optode mounted in previous DEEP experiment, was deployed at $30 \mathrm{~m}$ above the bottom (at $895 \mathrm{~m}$ depth) for 9 months at the head of the Canyon du Guilvinec located in the North of the Bay of Biscay $\left(46^{\circ} 55^{\prime} \mathrm{N}, 05^{\circ} 21^{\prime} \mathrm{W}\right)$. The data collected showed oxygen values oscillating within the range of natural values (mean oxygen concentration was $212 \mu \mathrm{M}$, with a maximum value of 279 $\mu \mathrm{M}$ and a minimum value of $180 \mu \mathrm{M}$ ) not affected by any significant drops in oxygen values (Fig. 8). Variations in oxygen concentrations may be correlated to tidal currents affecting vertical movements of water masses accentuated by the local steep topography. Surprisingly, the optode performance is in complete contrast with data collected by the same instrument during the DEEP experiment. The reason for this may be seen in the overall much higher current speeds at the Canyon de Guilvinec (mean current speed of $18 \mathrm{~cm} \mathrm{~s}^{-1}$, varying between $0.2 \mathrm{~cm} \mathrm{~s}^{-1}$ and $70.5 \mathrm{~cm} \mathrm{~s}^{-1}$ ) 
as well as to shorter low current periods than during the DEEP experiment. These latter dataset confirms definitely that the problem encountered during previous experiments could depend on low current regime and was not attributable to any natural cause.A simple hypothesis explaining these anomalies might refer to corrosion related to the sacrificial anode mounted on the current meter vessel. In fact, reduced currents may may contribute to stagnation of reduced oxygen concentrations around the sensor head due to ongoing oxygen consumption by the corroding anode. Furthermore, experiments using coupled RCM11-optode systems (protected by an anode) as well as optodes with cable connections to the RCM11 on free-falling systems (bottom-lander) at HAUSGARTEN showed that episodically drops in the optode readings were well recorded by all sensors, raising the presumption that corrosion by any metallic part in the vicinity of the optode (including sacrificial anodes, bottom-lander weights and/or the entire lander frame) might disturb the measurement of the optode in low current regimes.

By now, there is no final answer to the encountered problem. If the drops in the oxygen reading are exclusively caused by corrosion effects the use of a pump system flushing the optode sensor might help to clear the readings from the anomalies occurring in low-energy environments. However, drops in oxygen concentrations encountered in all discussed experiments were sometimes extremely high (up to $100 \mu \mathrm{M}$ ) and there are still doubts whether corrosion in the vicinity of the optode might cause that large effects. Appropriate tests should be carried by the manufacturer to get a grip on the optode anomalies as determined in deep water / low-energy environments. In the meantime, for all application in deep waters or, more generally, in all environments characterized by weak hydrodynamics, it is indispensable monitor the current intensities, in order to be able to verify optode data reliability. 
Acknowledgements: We thank the captains and crews of the R/V Atalante, R/V Suroit, R/V Tethys II, R/V Pourquoi Pas?, and R/V Polarstern. Scientific and technical staffs of the Ifremer and the Alfred Wegener Institute for Polar and Marine Research are warmly acknowledged.

A special thanks goes to all people that participate and contribute to all occurred discussion to understand the possible origin of the encountered problem.

This research was partially supported by ANR EXTREMA and the HERMES project (EC contract $\mathrm{n}^{\mathrm{o}}$ GOCE-CT-2005-511234, funded by the European Commission). This publication reflects only the views of the authors and the EC is not liable for any use that may be made of the information contained therein.

\section{References :}

ATC, 2004. Performance verification statement for Aanderaa Instruments Inc. Dissolved Oxygen Optode 3830/3980/3835.

Hydes, D.J., Hartman, M.C., Kaiser, J., Campbell, J.M., 2009. Measurement of dissolved oxygen using optodes in a FerryBox system. Estuarine, Coastal and Shelf Science 83 (4), 485-490.

Körtzinger, A., Schimanski, J., Send, U., 2005. High Quality Oxygen Measurements from Profiling Floats: A Promising New Technique. Journal of ATmospheric and Oceanic Technology 22 (3), 302308.

Körtzinger, A., Schimanski, J., Send, U., Wallace, D., 2004. The Ocean Takes a Deep Breath. Science 306 (5700).

Martini, M., Butman, B., Mickelson, M.J., 2007. Long-Term Performance of Aanderaa Optodes and Sea-Bird SBE-43 Dissolved-Oxygen Sensors Bottom Mounted at $32 \mathrm{~m}$ in Massachusetts Bay. Journal of ATmospheric and Oceanic Technology 24 (11), 1924-1935.

Schmidt, C., Vuillemin, R., Le Gall, C., Gaill, F., Le Bris, N., 2008. Geochemical energy sources for microbial primary production in the environment of hydrothermal vent shrimps. Marine Chemistry 108 (1-2), 18-31.

Soltwedel, T., Bauerfeind, E., Bergmann, M., Budaeva, N., Hoste, E., Jaeckisch, N., Von Juterzenka, K., Matthiessen, J., Mokievsky, V., Nothig, E.-M., Quéric, N.-V., Sablotny, B., Sauter, E., Schewe, I., Urban-Malinga, B., Wegner, J., Wlodarska-Kowalczuk, M., Klage, M., 2005. Hausgarten:Multidisciplinary Investigations at a Deep-Sea, Long-Term observatory in the Arctic Ocean. Oceanography 18(3), 46-61.

Tengberg, A., Hovdenes, J., Andersson, H.J., Brocandel, O., Diaz, R., Hebert, D., Arnerich, T., Huber, C., Körtzinger, A., Khripounoff, A., Rey, F., Rönning, C., Schimanski, J., Sommer, S., Stangelmayer, A., 2006. Evaluation of a lifetime-based optode to measure oxygen in aquatic systems Limnology and Oceanography: methods, pp. 7-17. 
Tengberg, A., Hovdenes, J., Barranger, D., Brocandel, O., Diaz, R., Sarkkula, J., Huber, C., Stangelmayer, A., 2003. Optodes to measure oxygen in the aquatic environment. Sea Technology 44, 189-195.

Uchida, H., Kawano, T., Kaneko, I., Fukasawa, M., 2008. In Situ Calibration of Optode-Based Oxygen Sensors. Journal of ATmospheric and Oceanic Technology 25 (12), 2271-2281.

Vangriesheim, A., 2007. Mesure d'oxygène par optode installée sur un courantomètre Aanderaa Rcm11. Cas des données des campagnes Exomar 2005 et Envar 4 et 5 (2006, 2007). Rapport.Interne. DEEP/LEP 07-14. 


\section{Figure 1:}
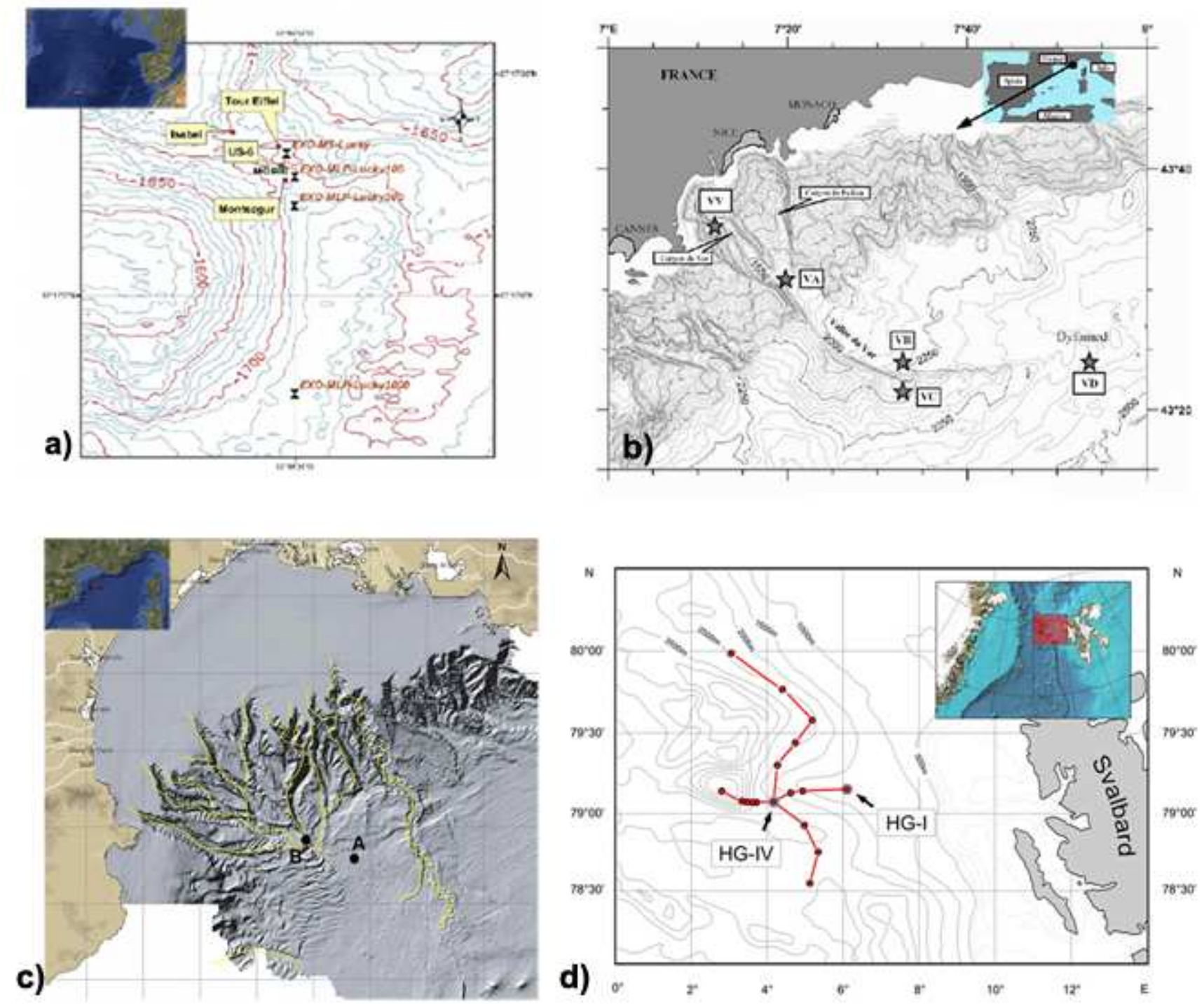
Figure 2:
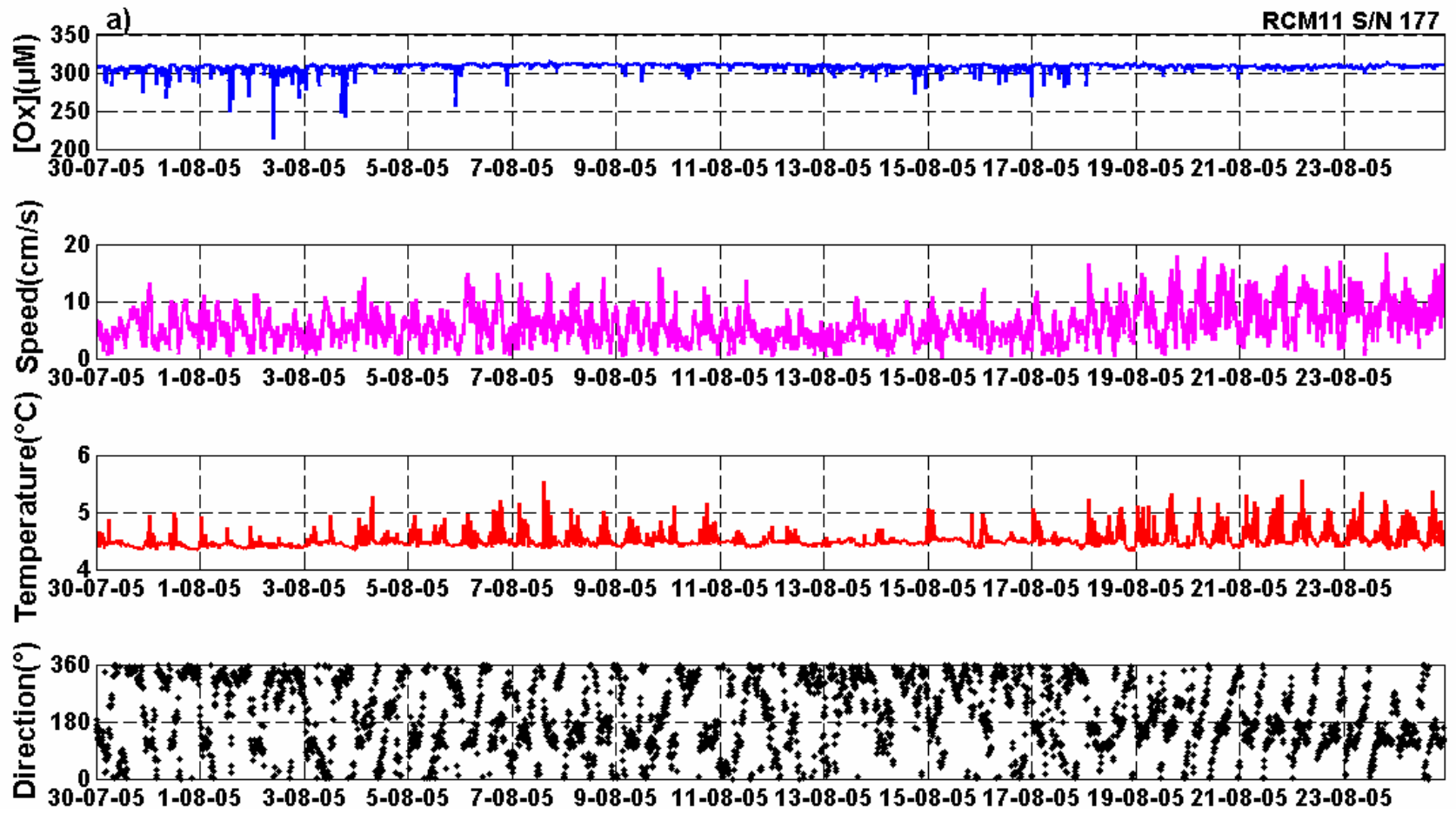

b)
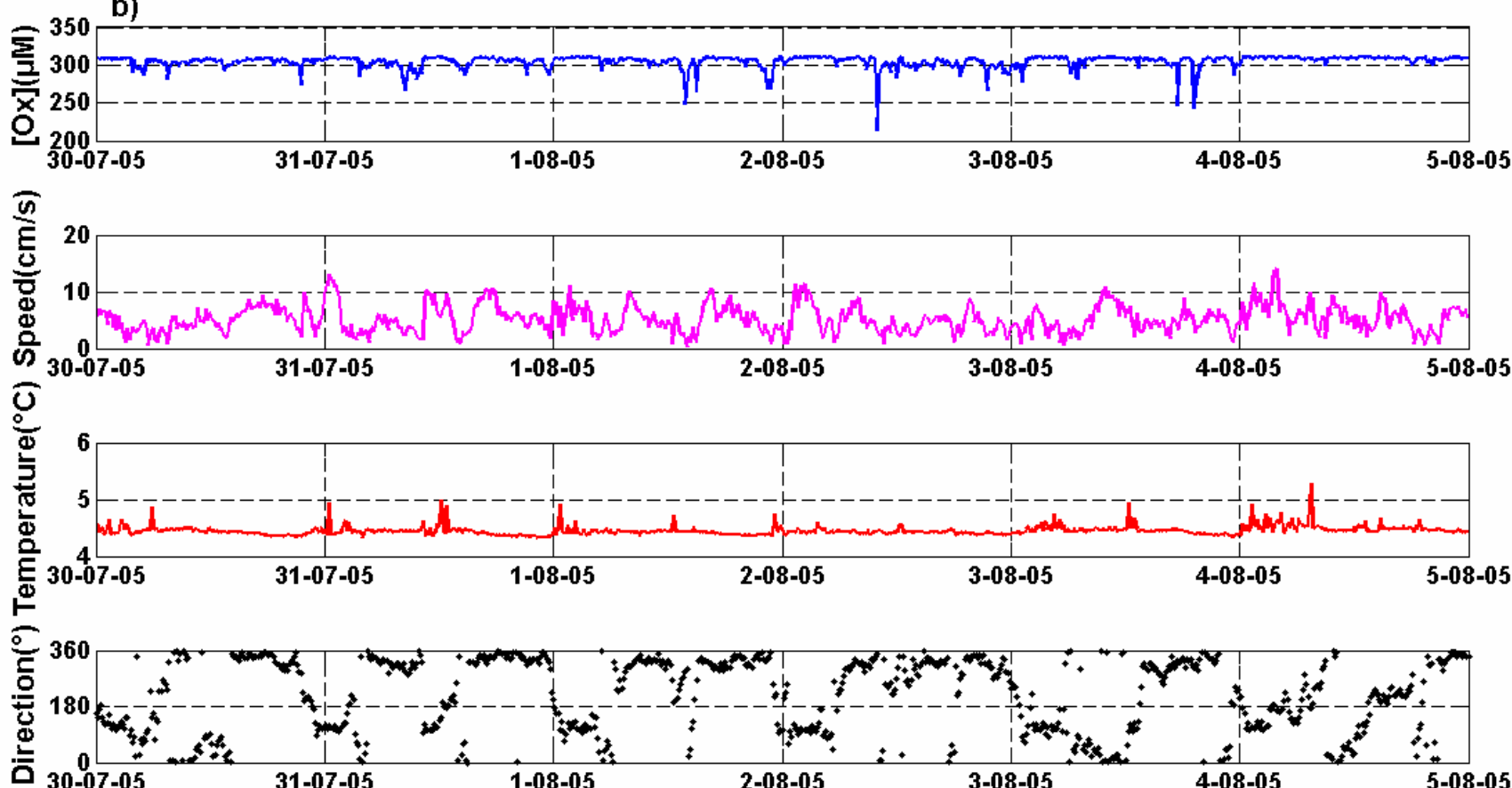
Figure 3:

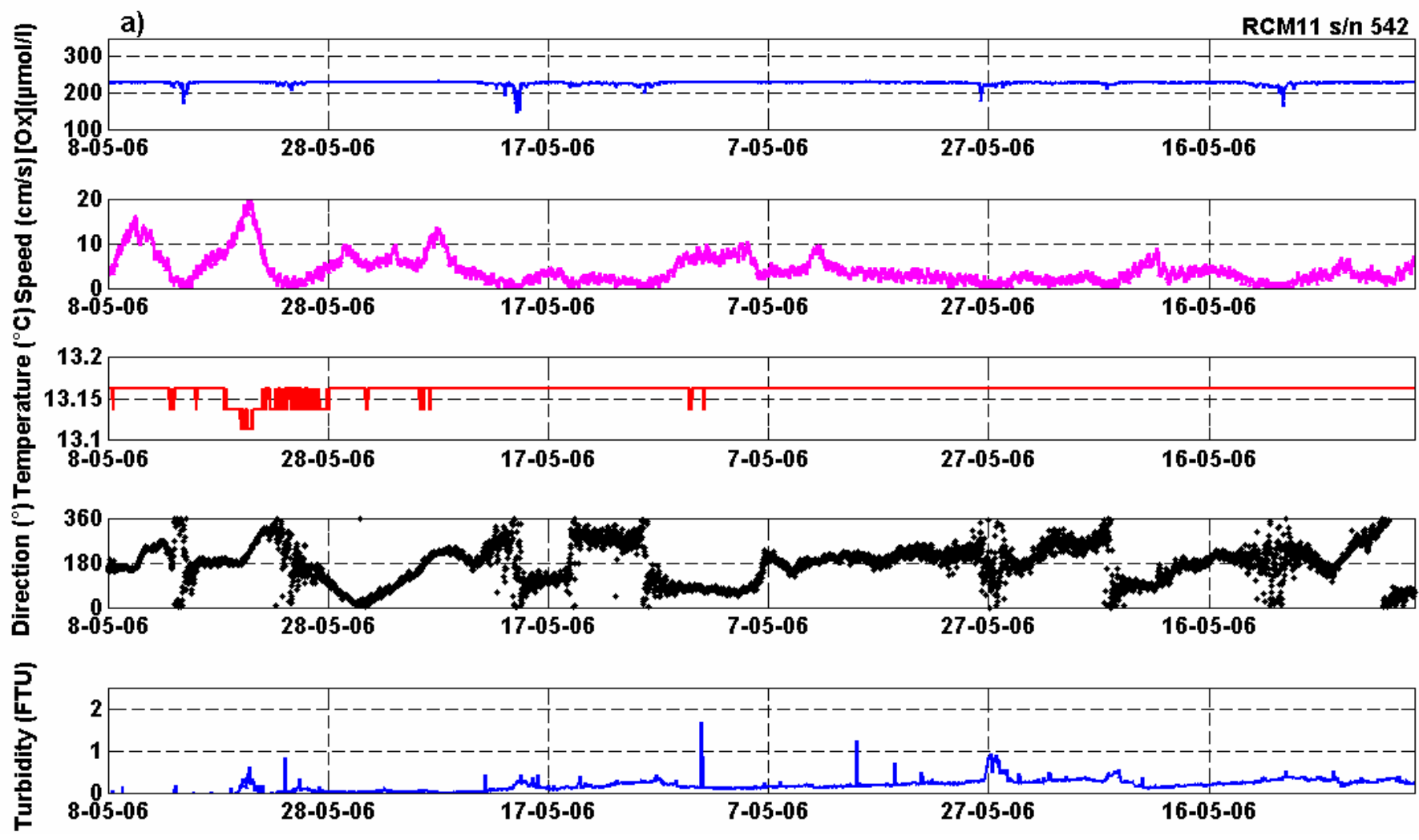

b)

RCM11s/n 542
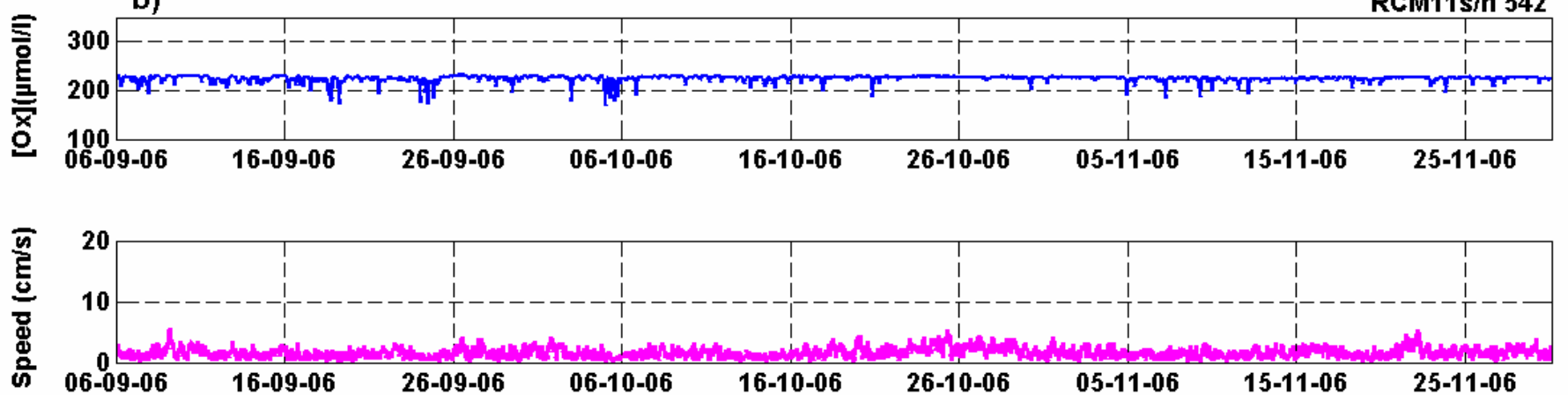

0
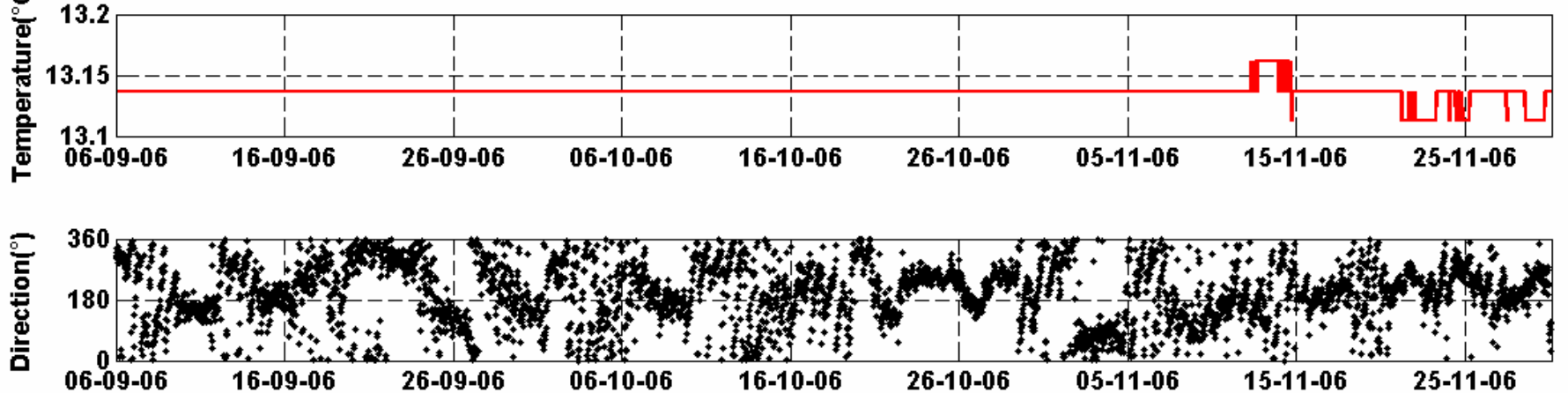
Figure 4:

a)

RCM11s/n 177 and 542
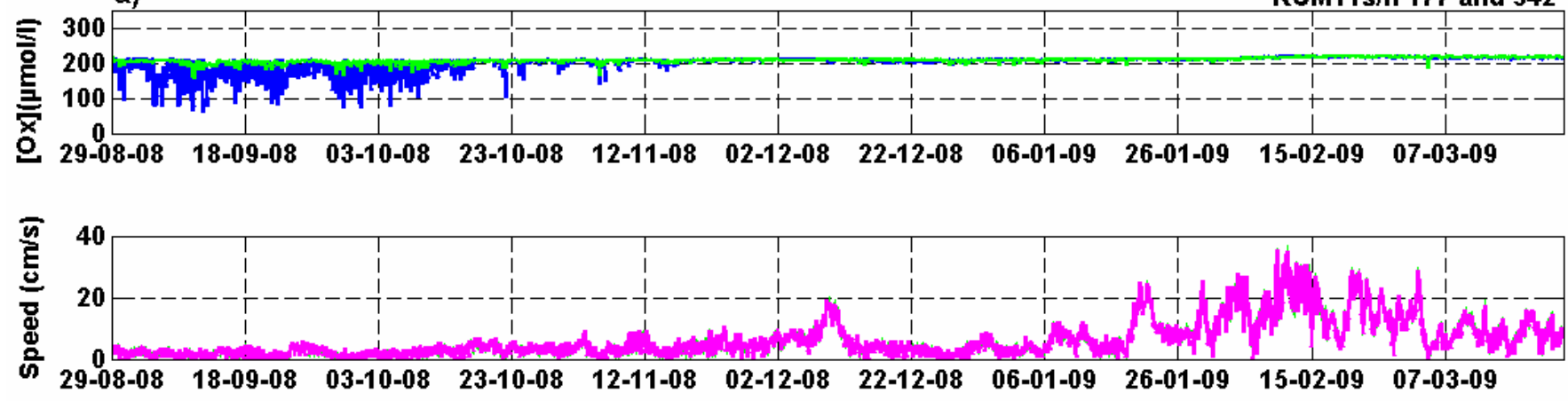

$\bar{\sigma}$
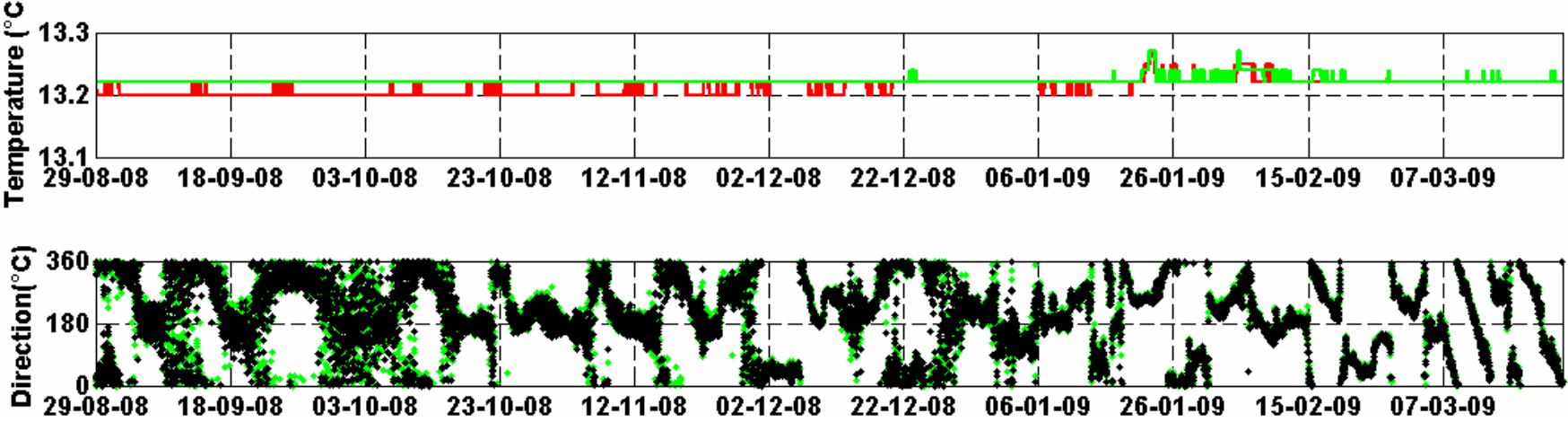

b)

RCM11 sin 625
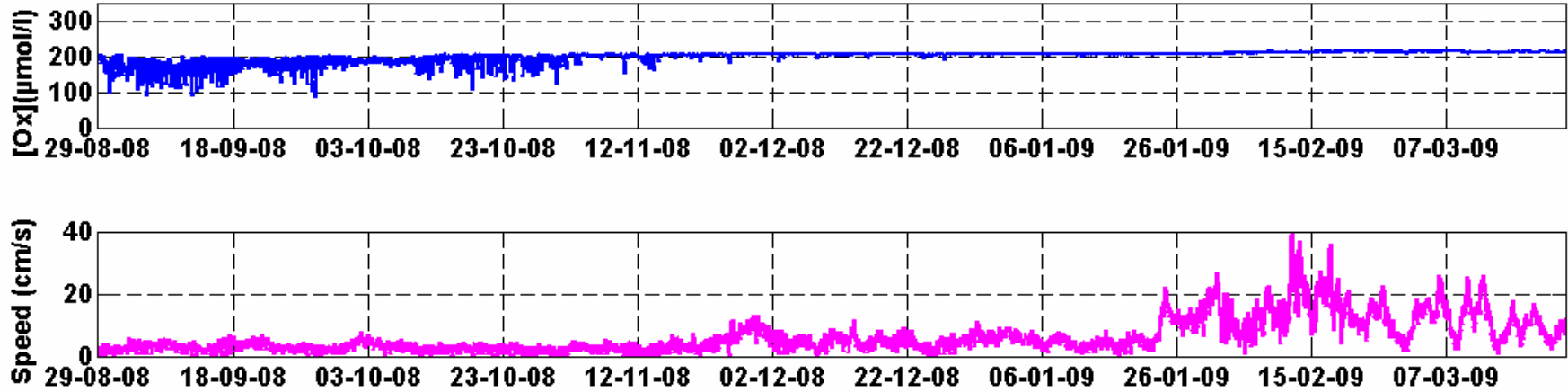

늘

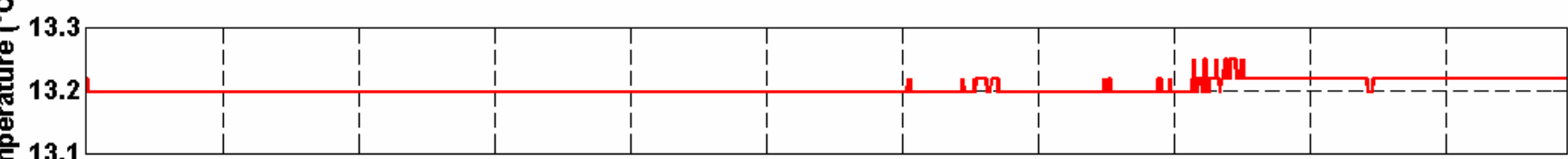

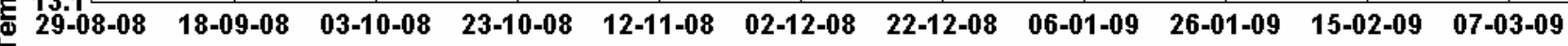

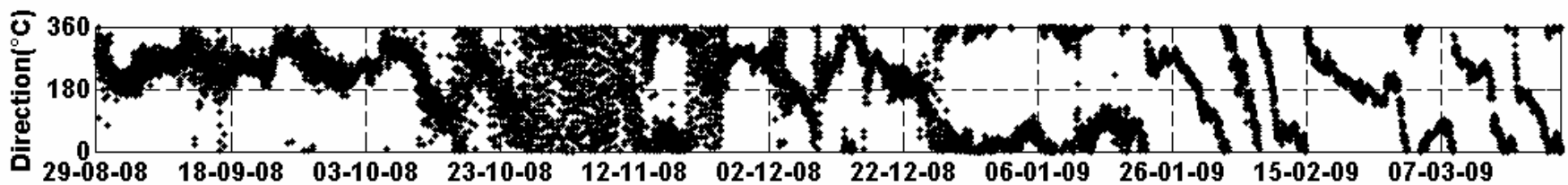




\section{Figure 5:}

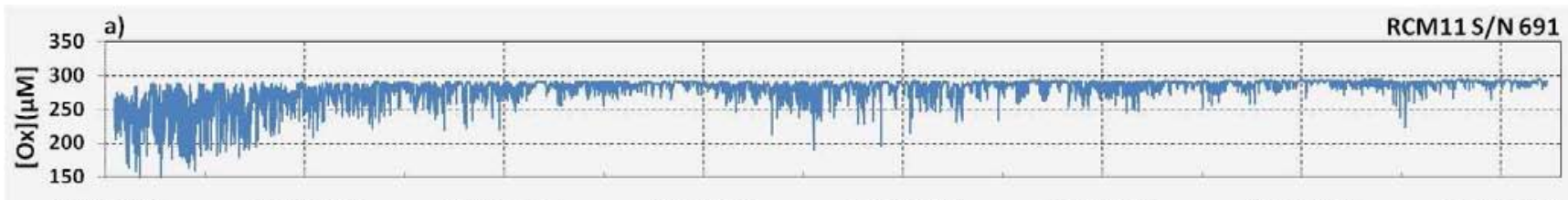

$\begin{array}{rrrrrrr}11.07 .2009 & 30.08 .2009 & 19.10 .2009 & 08.12 .2009 & 27.01 .2010 & 18.03 .2010 & 07.05 .2010\end{array}$
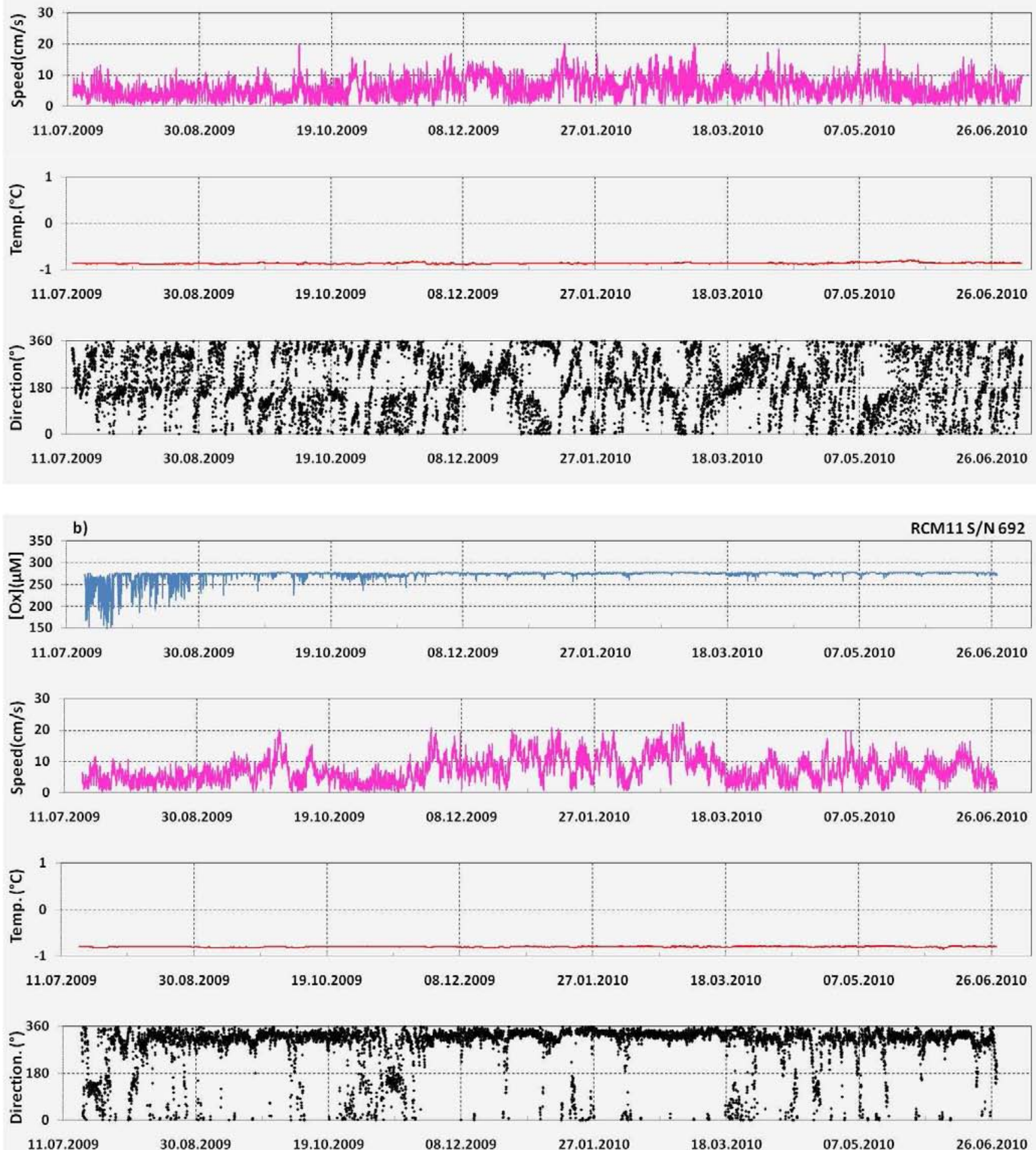


\section{Figure 6:}

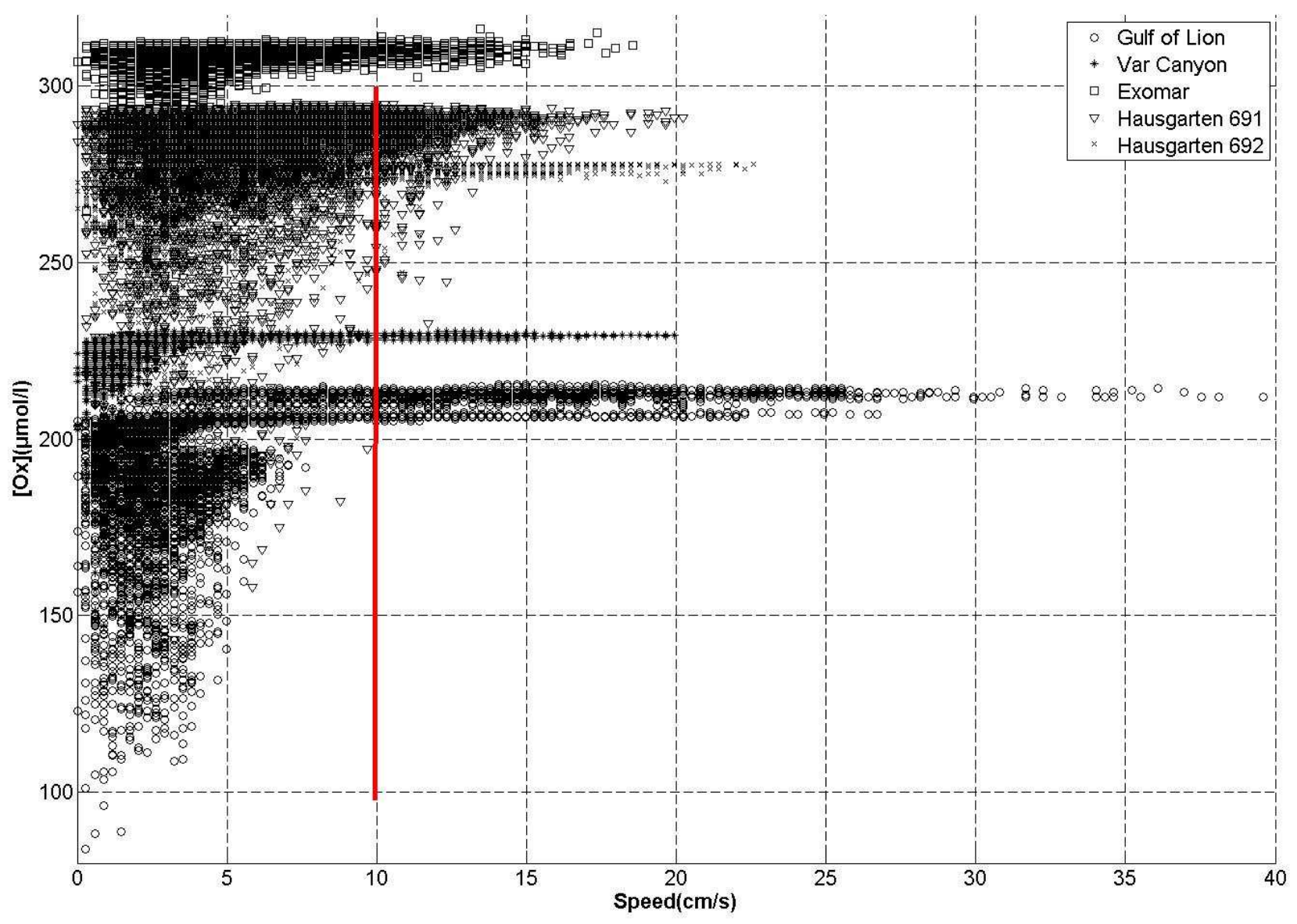




\section{Figure 7:}

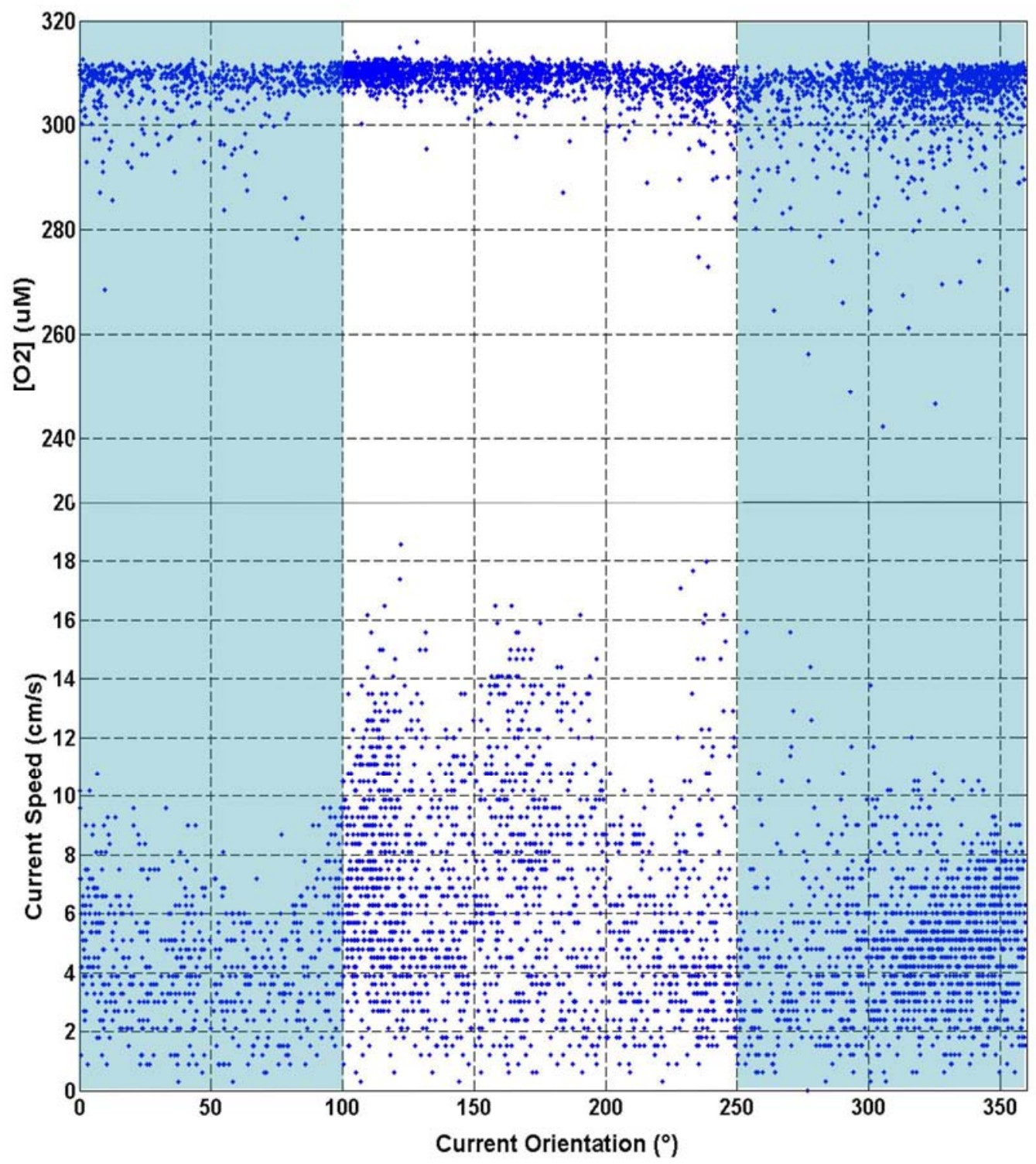


Figure 8:
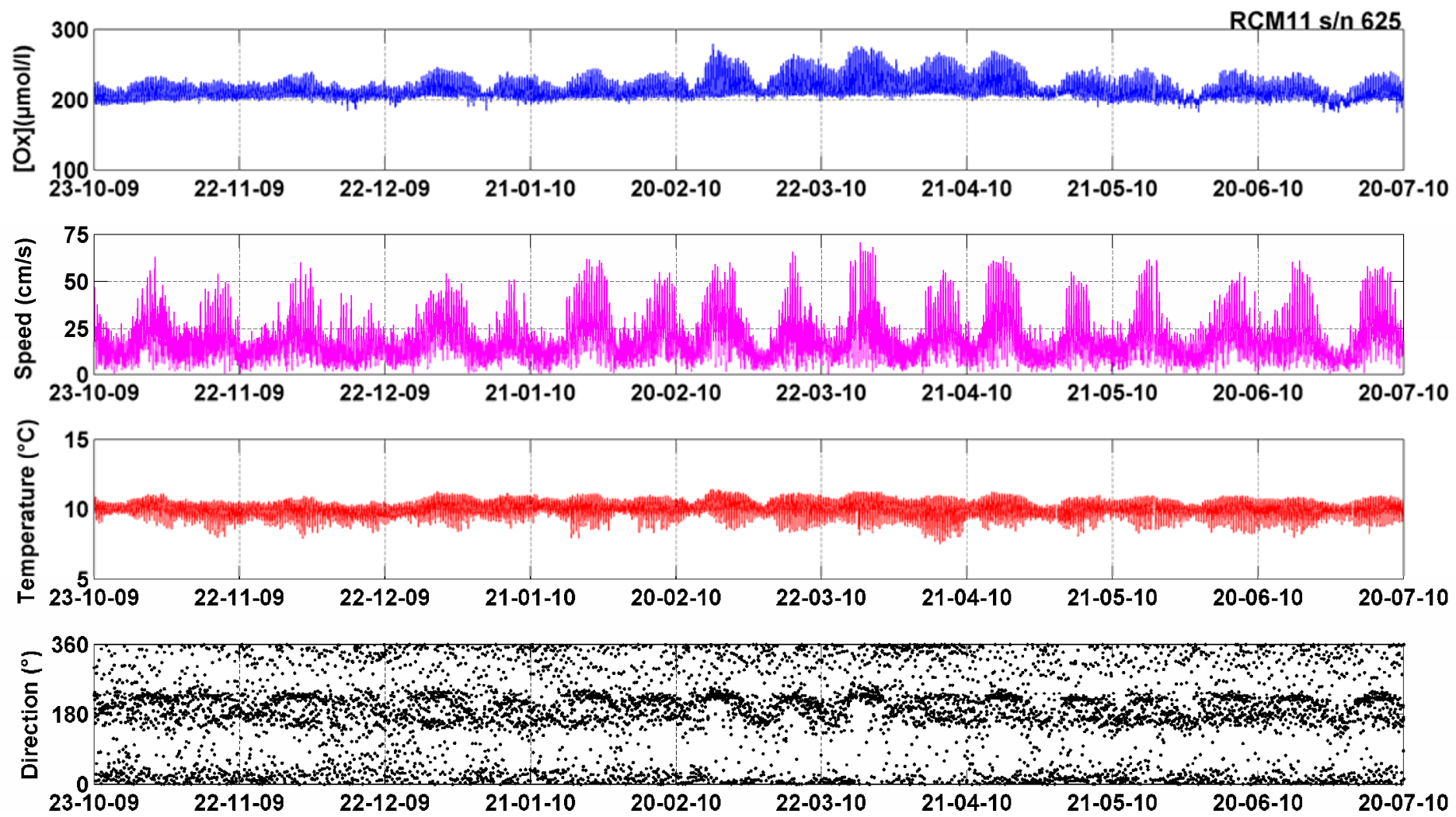